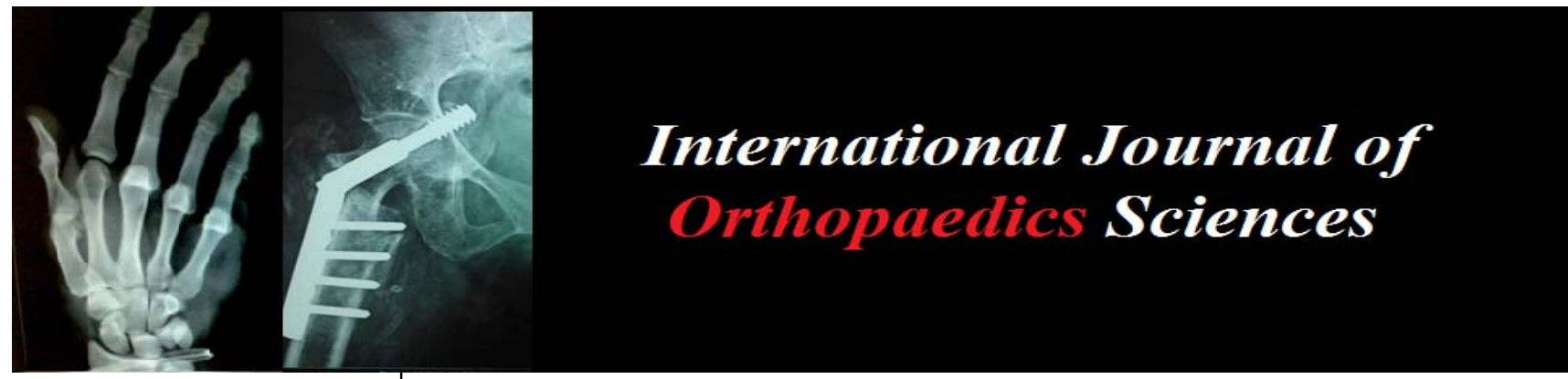

ISSN: $2395-1958$

IJOS 2017; 3(1): 152-161

(C) 2017 IJOS

www.orthopaper.com

Received: 25-11-2016

Accepted: 26-12-2016

Amira Alrshood

Salford University, United

Kingdom

Adel El Alwani

Higher Institute of Medical

Professions-Benghazi - Libya

Naser Amein

Higher Institute of Medical

Professions- Benghazi - Libya

Mussa El Mughrabi

Higher Institute of Medical

Professions- Benghazi - Libya

Salima Enaiba

Faculty of Medical Technology-

Misurata - Libya

Dr. Adel Almangoush

Faculty of Medical Technology-

Misurata - Libya
Correspondence

Dr. Adel Almangoush

Faculty of Medical Technology-

Misurata - Libya

Salford2013@gmail.com

\section{A systematic review of the effect of open and closed kinetic chain exercises on the vastus medialis oblique and vastus lateralis muscles of patients with patellofemoral pain syndrome}

\author{
Amira Alrshood, Adel El Alwani, Naser Amein, Mussa El Mughrabi, \\ Salima Enaiba and Dr. Adel Almangoush
}

DOI: http://dx.doi.org/10.22271/ortho.2017.v3.i1c.25

\section{Abstract}

Objectives: The purpose of the present study is to review the existing literature regarding the response of the vastus medialis oblique (VMO) and vastus lateralis (VL) muscles of patients with patellofemoral pain syndrome (PFPS) to open and closed kinetic chain exercises.

Search methods: A search was conducted for randomised and non-randomised controlled trials published by July 2016 and involving comparative analysis of exercise treatment with control groups or various exercise treatment types. The following resources were searched: the Cochrane Bone, Joint and Muscle Trauma Group and Cochrane Rehabilitation and Related Therapies Field specialised registers, the Cochrane Controlled Trials Register, The Physiotherapy Evidence Database (PEDro), MEDLINE, EMBASE, and CINAHL.

Data collection and analysis: Trials were excluded if they were not concerned with exercise therapy in individuals with PFPS. Thus, only nine out of 91 trials found were included and they all employed statistical techniques to assess the response of VMO and VL muscles to open and closed kinetic chain exercises.

Main results: The trials under review are too few in number and are inconsistent with regard to rehabilitation strategies and outcome assessment. They underline the necessity for reviewing RCT trials on a wider scale as the evidence they supply in support of use of open and closed kinetic chain exercises is insufficient. Trials have to be comparable in terms of participant traits, intervention and outcome assessment to improve the validity of the conclusions drawn. It was not possible to definitely say whether one intervention was better than another, because different interventions were implemented in the reviewed trials. Furthermore, future research should also include placebo-controlled trials to ascertain the efficiency of various interventions.

Keywords: Kinetic chain exercises, vastus medialis oblique, vastus lateralis muscles, patellofemoral pain syndrome

\section{Introduction}

The patellofemoral pain syndrome (PFPS) is a retropatellar or peripatellar pain caused by patellofemoral joint modifications of a physical and biomechanical nature. Individuals with painful knees often receive a diagnosis of PFPS (Lankhors, Bierma-Zeinstra and van Middelkoop, 2012) ${ }^{[29]}$, which is worsened by performance of activities like stair climbing/descending, squatting, or prolonged sitting with knees in a flexed position (Lankhors et al. 2012) ${ }^{[29]}$. This condition has a prevalence of $22 / 1000$ person years and women, particularly those between 18 and 35 years of age (Roush and Bay, 2012), are twice as likely to be affected compared to men (Boling et al., 2010) ${ }^{[2]}$. Moreover, PFPS accompanies a quarter of knee injuries sustained during sports (Fredericson and Yoon, 2006) ${ }^{[15]}$, yet no comprehensive understanding has been achieved regarding how this condition develops and how it is classified, diagnosed and treated. However, many researchers have concurred that PFPS is not the outcome of just one, but several causative factors (Nunes et al., 2013) ${ }^{[32]}$, including excessive use, trauma, anatomical aspects, inadequate muscle functioning, 
and abnormal lower limb alignment (Lankhors et al., 2012)

${ }^{[29]}$. Additionally, quadriceps deficiency or atrophy, especially imbalanced movement of quadriceps components, is considered the main biochemical factor underpinning PFPS development, although conclusive evidence has not been produced so far (Nunes et al., 2013; Giles et al., 2013) ${ }^{[32] .}$

The vastus lateralis (VL) muscle supports the lateral movement of the patella while the vastus medialis muscle, especially the vastus medialis oblique (VMO), supports the medial patellar movement. The fibres of the VMO are angled almost horizontally $\left(50-55^{\circ}\right)$ with regard to the shaft of the femur, serving more to stabilise the patella medially rather than contributing significantly to knee extension (Miao et al., 2015) [31]. Despite the fact that their efficiency is unclear, exercises meant to strengthen the VMO are frequently prescribed to PFPS sufferers (Powers, 2000) ${ }^{[35]}$. Double-leg semi-squate with hip adduction and squats with concomitant squeezing of a ball between knees are two of the exercises commonly prescribed to rehabilitate PFPS. Nonetheless, as observed by Bolgla and Malone (2005) ${ }^{[3]}$, there is not enough objective evidence to confirm that such exercises are indeed efficient.

The exercises typically prescribed to strengthen the VMO can be classified into two categories, namely, open and closed kinetic chain exercises. One study reported that exercises meant to extend the knee at varying angles between $0^{\circ}$ and $60^{\circ}$ resulted in VMO activation (Dannelly et al., 2011) ${ }^{[12]}$. As explained by Fagan and Delahunt (2008) ${ }^{[13]}$, exercises for knee extension pull the patella within the trochlear groove of the femur by the quadriceps and cranial slides, and therefore are deemed to correct the imbalance between the VMO and VL that characterises PFPS, and in this way, they make patellar tracking more stable. Meanwhile, according to Lam and $\mathrm{Ng}$ (2001) ${ }^{[27]}$, both open and closed kinetic chain exercises contributed to alleviation or prevention of PFPS.

Despite the fact that their efficiency remains a matter of debate, open chain leg extension exercises are often recommended in clinical practice to engage the VMO (Laprade, Culham and Brouwer, 1998) ${ }^{[28]}$. Open kinetic chain exercises involve moving just one joint with no weight bearing and a free distal extremity. By contrast, closed kinetic chain exercises involve movement of more than one joint with weight bearing and a fixed distal extremity (Stensdotter et al., 2003) ${ }^{[43]}$.

\subsection{Literature search}

Earlier reviews were searched in order to assess the comprehensiveness with which the subject under consideration has been investigated. Results suggested that the response of the VMO and VL muscles of PFPS patients to open or closed kinetic chain exercises was not addressed by any of the studies reviewed.

\subsection{Current reviews}

The focus of the review conducted by Smith et al. (2009a) ${ }^{[39]}$ was on considerations such as the attachment of the vastus medialis (VM) muscle to the patella and the extent of this attachment, how long the distal VM tendon was, and whether these aspects underpinned the aetiology of patellofemoral conditions. A number of eight studies were obtained from electronic and manual search of works published in English and concerned with examination of how the distal VM attached to the patella based on cadaver dissection or radiography. According to the results, in most cases, the attachment of the distal VM was proximal or at the midpoint of the patella. Furthermore, it was found that the distal VM attached to the patella in a proportion of $10 \%$ of its length, and the distal VM tendon was between 1.4 and $3.5 \mathrm{~cm}$ long. However, the insufficiency of comprehensive studies on this topic hindered formulation of conclusions as to whether these aspects contributed to patellofemoral condition aetiology.

The review conducted by Smith et al. (2009b) ${ }^{[40]}$ focused on determining whether preferential strengthening could be achieved through greater activation of the VMO compared to the VL by modifying how the joints of the lower limbs are oriented or how different muscles contract together. The review encompassed a number of twenty studies with an overall sample size of 387 participants. The results of most of these studies indicated that VMO was not preferentially activated over VL based on modification of lower limb joint orientation or muscle co-contraction. Furthermore, several notable shortcomings of methodology were distinguished. Therefore, to address these shortcomings and accomplish a comprehensive exploration of the subject, the authors suggested that future research must have a better design and include larger numbers of participants with patellofemoral joint problems.

To the current researcher's knowledge, this topic has not been approached by any other previous study, which means that the results of this study will be significant for both PFPS patients and for professionals in charge of exercise therapy.

\subsection{The review question}

The researchers do not know of any randomised controlled trials concerned with VMO and VL response to open and closed kinetic chain exercises among PFPS patients that have been systematically reviewed. Therefore, the present study, is the first to review randomised clinical trials in a thorough and systematic manner.

\section{Objectives}

- To systematically evaluate how efficient open and closed kinetic chain exercises are in activating the VMO and VL muscles of PFPS patients;

- To compare how different open and closed kinetic chain exercises influence VMO and VL activity and therapeutic interventions;

- To identify what are the most efficient open and closed kinetic chain exercises.

\subsection{Methods}

A systematic review can be understood as a methodological tool with which the literature associated with a specific subject can be searched and examined to achieve a certain aim (Collins and Fraser, 2005) ${ }^{[8]}$. Similarly, Cronin Ryan and Coughlan, (2008) ${ }^{[11]}$ explained that the systematic review employs specific factors of identification, evaluation and compilation to scrutinise all published and unpublished works related to a topic.

The systematic review is considered the ideal strategy for investigating randomised control trials (RCTs) because it helps to avoid bias in interpretation that direct selection of studies by the researcher may engender.

\subsection{Search strategy}

The study was undertaken an electronic search of relevant journals, books, conference proceedings and reference lists, as well as a manual search with inclusion of all published and unpublished works written in English and related to the subject in question. Both abstracts and full texts were examined. 


\subsection{Criteria for inclusion in the study}

The study will employ specific inclusion and exclusion criteria in order to ensure that the systematic review will yield interpretations and conclusions that are pertinent and objective. This is in keeping with Rochon et al. (2005) ${ }^{[36]}$, who suggested that, to obtain unbiased findings, a review should only encompass works that demonstrate certain aspects or features. Thus, the search in this study will be guided by the following criteria:

\subsection{Study type}

To accomplish the research goal, the study design of randomised controlled trial (RCT) has been chosen so that the efficiency of therapeutic interventions can be assessed impartially (Britton and Cousins, 1998) ${ }^{[5]}$. Because it selects and organises participants randomly, the RCT is deemed the 'gold standard' in clinical research (Greenhalgh, 2001; Concato, Shah and Horwitz, 2000) ${ }^{[9]}$ and is underpinned by quantitative methodology since it is geared towards measuring outcomes with regard to intervention groups.

\subsection{Types of participants}

To be included in the review, studies had to examine both male and female participants in the age range 18-40 years old, suffering from PFPS in at least one lower limb (Syme et al., 2009) ${ }^{[44]}$.

\subsection{Forms of interventions}

Every study that employed conventional open and closed kinetic chain exercises for lower extremities and proprioceptive rehabilitation programs for the VMO and VL muscles was included in the review.

\subsection{Outcome measures}

As highlighted by Megens and Harris (1998) ${ }^{[30]}$, the research outcome measures are highly important, determining how reliable the findings are as well as how robust and valid the entire research is. For research to be considered valid, it must be based on outcomes grounded in reliable data. The primary outcome measures employed in this systematic review are static postural control (SPC) and dynamic postural control (DPC) for PFPS patients. In addition, two flexible electrogoniometers are used to measure the flexion and extension angles of the knee in relation to time (Rower et al., 2001) [37], whilst heel and toe foot-switches for each foot enable the determination of gait stance and swing phases.

\subsection{Exclusion criteria}

Comments, letters, editorials, protocols, guidelines, abstracts, conference proceedings, review papers, unpublished papers, such as university theses and dissertations, studies relying on animal models, and studies written in languages other than English were all excluded from the review so as to make sure that every original work was critically evaluated.

\section{Data collection and analysis \\ 3.1 The study selection process}

The subjectivity of the individual performing the selection process may skew the choice of studies included in the review. This issue can be avoided if a minimum of two reviewers undertake the process of selection once the relevant studies have been determined, so as to prevent bias and ensure the impartiality of the selection (Higgins and Green, 2006) ${ }^{[21] .}$

\subsection{Study selection}

As mentioned earlier, the researcher was the only reviewer of the studies obtained from the search of the literature, owing to restrictions of time and resources. All studies that met the selection criteria were thoroughly read by the researchers to ensure their relevance with regard to the subject under investigation.

\subsection{Data collection}

According to Van de Voorde and Leonard (2007) [46], representation of acquired data in a visual manner can facilitate the assessment of the selected studies. The standardised collection of data was undertaken in keeping with a number of criteria, including information related to publication, research question, research design, experiment techniques, randomisation, binding, information related to participants, such as inclusion and exclusion criteria and recruitment, as well as findings related to intervention outcomes.

\subsection{Data analysis and synthesis}

As suggested by Higgins and Green (2006), meta-analysis can enable the measurement of the impact of open and closed kinetic chain exercises on the VMO and VL muscles. This is a statistical technique designed to synthesise data from several identical studies. The narrative method of systematic representation is employed to analyse and compare the research results in the event that identical studies are not available. Furthermore, adverse effects and withdrawal rates can be recorded as well, provided that the data allow it. If trials are non-uniform, then additional outcomes may be evaluated.

\subsection{The process of search}

The electronic databases AMED, CINAHL, the Cochrane database, EMBASE, ovid Medline, Physiotherapy Evidence Database (PEDro), and Pubmed were searched from their first issue to August 2016. The keywords used to structure the search were chosen based on their sensitivity rather than their specificity (White and Schmidt, 2005) ${ }^{[49]}$ and encompassed "vastus medialis", "vastus medialis obliquus", "VMO", "anatomy", "vastus lateralis", "VL", "open kinetic chain exercise", "closed kinetic chain exercise", "exercise therapy", and "patellofemoral pain syndrome". The keywords were deliberately non-specific so that the search would yield all the works of potential relevance. Furthermore, the search of electronic databases was supplemented with a manual search. 
Table 1: Data extraction table

\begin{tabular}{|c|c|c|c|c|c|}
\hline $\begin{array}{l}\text { publication } \\
\text { details }\end{array}$ & $\begin{array}{l}\text { the research question } \\
\text { and purpose }\end{array}$ & $\begin{array}{l}\text { participant } \\
\text { characteristics }\end{array}$ & $\begin{array}{c}\text { Physiotherapy exercise } \\
\text { modality }\end{array}$ & $\begin{array}{c}\text { Outcome } \\
\text { measurements } \\
\text { function, pain, and } \\
\text { QoL } \\
\end{array}$ & Findings \\
\hline $\begin{array}{l}\text { 1) Fehr et } \\
\text { al. (2006) }\end{array}$ & $\begin{array}{l}\text { To analyse the } \\
\text { therapeutic effects of } \\
\text { the open kinetic chain } \\
\text { (OKC) and closed } \\
\text { kinetic chain (CKC) } \\
\text { exercises to treat the } \\
\text { patellofemoral } \\
\text { syndrome (PFSD). }\end{array}$ & $\begin{array}{c}24 \\
\text { volunteers, bearers of } \\
\text { the PFSD were } \\
\text { randomly divided in } \\
\text { two } \\
\text { groups: group I ( } \mathrm{n}= \\
\text { 12) performed the } \\
\text { OKC exercises; group } \\
\text { II ( } \mathrm{n} \\
\text { 12) performed the } \\
\text { CKC exercises. }\end{array}$ & $\begin{array}{l}\text { Open \& closed Chain } \\
\text { exercises }\end{array}$ & $\begin{array}{l}\text { the electromyographic } \\
\text { signals (EMG) were } \\
\text { collected using bipolar } \\
\text { surface electrodes } \\
\text { quantified by the root } \\
\text { mean square (RMS) } \\
\text { to measure the pain } \\
\text { intensity upon the rest } \\
\text { and while performing } \\
\text { functional activities, } \\
\text { the VAS and the Kujala } \\
\text { scale were respectively } \\
\text { applied } \\
\end{array}$ & $\begin{array}{l}\text { The results found in } \\
\text { this study suggest } \\
\text { that according } \\
\text { to the conditions of } \\
\text { the trial, the OKC } \\
\text { and CKC exercises } \\
\text { provoke } \\
\text { no changes in the } \\
\text { patterns of the EMG } \\
\text { activation in the } \\
\text { VMO and } \\
\text { VL muscles. }\end{array}$ \\
\hline $\begin{array}{l}\text { 2) Laprade } \\
\text { et al., } 1998\end{array}$ & $\begin{array}{c}\text { Comparison of Five } \\
\text { Isometric Exercises in } \\
\text { the } \\
\text { Recruitment of the } \\
\text { Vastus Medialis } \\
\text { Oblique in } \\
\text { Persons With and } \\
\text { Without Patellofemoral } \\
\text { Pain Syndrome }\end{array}$ & $\begin{array}{c}19 \text { female control } \\
\text { subjects were } 24 \text { years, } \\
165.8 \mathrm{~cm} \text {, and } 58.9 \mathrm{~kg}, \\
\text { respectively. } \\
8 \text { female subjects with } \\
\text { PFPS were recruited } \\
\text { into the study. Were } 24 \\
\text { years, } 165.6 \mathrm{~cm} \text {, and } \\
60.9 \mathrm{~kg} \text {, respectively. }\end{array}$ & $\begin{array}{l}\text { Subjects performed two } \\
\text { submaximal isometric } \\
\text { contractions and one } \\
\text { maximal isometric } \\
\text { contraction }\end{array}$ & $\begin{array}{l}\text { The raw EMG signals } \\
\text { were recorded in all } \\
\text { subjects using bipolar } \\
\text { gold-plated }\end{array}$ & $\begin{array}{l}\text { No significant } \\
\text { differences in the } \\
\text { EMG VM0:VL } \\
\text { proportion were } \\
\text { found between } \\
\text { control subjects and } \\
\text { those with } \\
\text { patellofemoral } \\
\text { syndrome. }\end{array}$ \\
\hline $\begin{array}{l}\text { 3) Coqueiro } \\
\text { et al., } 2005\end{array}$ & $\begin{array}{l}\text { to investigate the effect } \\
\text { of hip adduction on the } \\
\text { activity of the Vastus } \\
\text { Medialis Obliquus } \\
\text { (VMO) and Vastus } \\
\text { Lateralis Longus } \\
\text { (VLL) muscles during } \\
\text { semisquat exercises. }\end{array}$ & $\begin{array}{c}\text { Ten healthy subjects } \\
\text { (age: } 21.8 \pm 2.52 \text { years } \\
\text { old } \\
\text { Ten sedentary PFPS } \\
\text { subjects (age: } 23.2 \pm \\
2.65 \text { years }\end{array}$ & $\begin{array}{l}\text { Double-leg semisquat } \\
\text { exercise } \\
\text { associated with hip } \\
\text { adduction (DLSS-HA) } \\
\text { isometric contraction \& } \\
\text { double-leg semisquat } \\
\text { (DLSS) exercise }\end{array}$ & $\begin{array}{l}\text { electromyographic } \\
\text { muscle The electrical } \\
\text { activity of the VMO } \\
\text { and VLL muscles } \\
\text { was detected by active } \\
\text { differential surface } \\
\text { EMG electrodes, } \\
\text { supplied by Lynx } \\
\text { Electronics } \\
\text { Technologies (Brazil). }\end{array}$ & $\begin{array}{l}\text { there was no } \\
\text { preferential VMO } \\
\text { muscle activation, }\end{array}$ \\
\hline $\begin{array}{l}\text { 4) Santos et } \\
\text { al. }(2008\end{array}$ & $\begin{array}{l}\text { The purpose of this } \\
\text { study was to evaluate } \\
\text { the amplitude and } \\
\text { onset of electrical } \\
\text { activation of the vastus } \\
\text { medialis obliquus } \\
\text { (VMO), vastus lateralis } \\
\text { longus (VLL) and } \\
\text { vastus lateralis } \\
\text { obliquus (VLO) during } \\
\text { functional activities in } \\
\text { individuals with } \\
\text { patellofemoral } \\
\text { pain syndrome (PFPS). }\end{array}$ & $\begin{array}{l}\text { Twenty women } \\
\text { participated in the } \\
\text { study: ten in a control } \\
\text { group and ten in the } \\
\text { group with PFPS. }\end{array}$ & $\begin{array}{c}\text { The } \\
\text { electromyographic signal } \\
\text { of the quadriceps muscle } \\
\text { was detected using } \\
\text { simple active differential } \\
\text { surface electrodes and a } \\
\text { four-channel } \\
\text { electromyography } \\
\text { system, during open } \\
\text { kinetic chain activities } \\
\text { (using an isokinetic } \\
\text { dynamometer) and closed } \\
\text { kinetic chain activities } \\
\text { (step and squat } \\
\text { maneuvers). }\end{array}$ & $\begin{array}{l}\text { To measure VMO } \\
\text { activity, a standard } \\
\text { MyoTrac biofeedback } \\
\text { device was used } \\
\text { (Premier Medical, } \\
\text { Kent, WA). }\end{array}$ & $\begin{array}{c}\text { : Under the } \\
\text { experimental } \\
\text { conditions } \\
\text { used, this study } \\
\text { suggests that there } \\
\text { is an imbalance in } \\
\text { the electric activity } \\
\text { and abnormal } \\
\text { recruitment patterns } \\
\text { among the VMO, } \\
\text { VLL and } \\
\text { VLO muscles in } \\
\text { individuals with } \\
\text { PFPS, with greater } \\
\text { delay and lower } \\
\text { amplitude of } \\
\text { activation of the } \\
\text { VMO in this group. }\end{array}$ \\
\hline $\begin{array}{l}\text { 5) syme et } \\
\text { al., } 2006\end{array}$ & $\begin{array}{l}\text { to compare the effects } \\
\text { of rehabilitation with } \\
\text { emphasis on } \\
\text { retraining the VMO } \\
\text { component of the } \\
\text { quadriceps femoris } \\
\text { muscle and } \\
\text { rehabilitation. }\end{array}$ & $\begin{array}{l}\text { Patients with PFPS (n } \\
=69)\end{array}$ & $\begin{array}{l}\text { physiotherapy exercises } \\
\text { emphasising selective } \\
\text { activation and retraining } \\
\text { of the VMO muscle } \\
\text { relative to the VL muscle } \\
\text { was undertaken by using } \\
\text { a dual } \\
\text { channel surface } \\
\text { electromyographic } \\
\text { biofeedback unit }\end{array}$ & $\begin{array}{c}\text { Two flexible } \\
\text { electrogoniometers } \\
\text { were used to measure } \\
\text { knee flexioneextension } \\
\text { angles with respect to } \\
\text { time. } \\
\text { the Modified } \\
\text { Functional Index } \\
\text { Questionnaire (MFIQ) } \\
\text { and the Short } \\
\text { Form-36 Health } \\
\text { Evaluation } \\
\text { questionnaire (SF-36) }\end{array}$ & $\begin{array}{c}\text { This study did not } \\
\text { demonstrate } \\
\text { that rehabilitation } \\
\text { with selective VMO } \\
\text { exercise } \\
\text { significantly } \\
\text { improves outcome } \\
\text { above that provided } \\
\text { by general open and } \\
\text { closed chain } \\
\text { strengthening } \\
\text { exercises }\end{array}$ \\
\hline $\begin{array}{l}\text { 6) Boling et } \\
\text { al., } 2006\end{array}$ & $\begin{array}{l}\text { To determine the } \\
\text { effects of a weight- }\end{array}$ & $\begin{array}{l}\text { Twenty-eight subjects } \\
(14 \text { controls, } 14\end{array}$ & $\begin{array}{c}\text { The rehabilitation } \\
\text { program }\end{array}$ & $\begin{array}{l}\text { Electromyographic } \\
\text { onsets of the }\end{array}$ & $\begin{array}{c}\text { Subjects diagnosed } \\
\text { with PFPS }\end{array}$ \\
\hline
\end{tabular}




\begin{tabular}{|c|c|c|c|c|c|}
\hline & $\begin{array}{c}\text { bearing } \\
\text { rehabilitation program } \\
\text { on quadriceps and } \\
\text { gluteus medius } \\
\text { electromyographic } \\
\text { activity, pain, and } \\
\text { function in subjects } \\
\text { diagnosed with } \\
\text { patellofemoral pain } \\
\text { syndrome (PFPS). }\end{array}$ & $\begin{array}{l}\text { experimental) between } \\
\text { the ages of } 18 \text { and } 42 \\
\text { years were recruited. } \\
\text { For the experimental } \\
\text { group, we recruited } 5 \\
\text { men and } 9 \text { women } \\
\text { (age, } \\
246 y\end{array}$ & $\begin{array}{l}\text { consisted of weight- } \\
\text { bearing exercises that } \\
\text { focused on strengthening } \\
\text { the quadriceps and hip } \\
\text { abductor musculature }\end{array}$ & $\begin{array}{l}\text { vastus medialis oblique } \\
\text { (VMO } \\
\text { A visual analog scale } \\
\text { (VAS) and Functional } \\
\text { Index } \\
\text { Questionnaire (FIQ) }\end{array}$ & $\begin{array}{l}\text { responded favorably } \\
\text { and quickly to a } \\
\text { therapeutic exercise } \\
\text { program that } \\
\text { incorporated } \\
\text { quadriceps and hip } \\
\text { musculature } \\
\text { strengthening }\end{array}$ \\
\hline $\begin{array}{l}\text { 7) Song et } \\
\text { al., } 2009\end{array}$ & $\begin{array}{l}\text { The objective of this } \\
\text { study was to determine } \\
\text { the surplus effect of hip } \\
\text { adduction on the VMO. }\end{array}$ & $\begin{array}{c}\text { Eighty-nine patients } \\
\text { with PFPS participate } \\
\text { (69 females) mean age } \\
40.2(9.9)\end{array}$ & $\begin{array}{c}\text { Participants were } \\
\text { randomly assigned to } 1 \text { of } \\
3 \text { groups: hip adduction } \\
\text { combined with leg-press } \\
\text { exercise (LPHA group), } \\
\text { leg-press exercise only } \\
\text { (LP group), or no } \\
\text { exercise (control group). } \\
\text { Training consisted of } 3 \\
\text { weekly sessions for } 8 \\
\text { weeks. }\end{array}$ & $\begin{array}{l}\text { Ratings of worst pain } \\
\text { as measured with a } \\
\text { 100-mm visual analog } \\
\text { scale (VAS-W), } \\
\text { Lysholm scale scores, } \\
\text { and measurements of } \\
\text { VMO morphology } \\
\text { (including cross- } \\
\text { sectional area [CSA] } \\
\text { and volume) were } \\
\text { obtained before and } \\
\text { after the } \\
\text { intervention. }\end{array}$ & $\begin{array}{l}\text { Similar changes in } \\
\text { pain reduction, } \\
\text { functional } \\
\text { improvement, and } \\
\text { VMO hypertrophy } \\
\text { were observed in } \\
\text { both exercise } \\
\text { groups }\end{array}$ \\
\hline $\begin{array}{l}\text { 8) Kang et } \\
\text { al. (2014) }\end{array}$ & $\begin{array}{l}\text { This study aimed to } \\
\text { examine the effects of } \\
\text { closed kinetic chain } \\
\text { exercise using } \\
\text { electromyography } \\
\text { (EMG) biofeedback for } \\
\text { selective strengthening } \\
\text { of the vastus medialis } \\
\text { oblique } \\
\text { (VMO) on } \\
\text { patllofemoral joint pain } \\
\text { and functional } \\
\text { characteristics of } \\
\text { patllofemoral joint } \\
\text { muscles. }\end{array}$ & $\begin{array}{l}\text { The subjects of this } \\
\text { study were } 30 \\
\text { patellofemoral pain } \\
\text { syndrome (PFPS) } \\
\text { patients and they were } \\
\text { equally and randomly } \\
\text { assigned to a control } \\
\text { group (I), a closed } \\
\text { kinetic chain exercise } \\
\text { group (II), and an } \\
\text { EMG biofeedback } \\
\text { closed kinetic chain } \\
\text { exercise (III). }\end{array}$ & $\begin{array}{l}\text { a closed kinetic chain } \\
\text { exercise group }\end{array}$ & $\begin{array}{c}\text { Surface EMG } \\
\text { (MyoTraceTM 400, } \\
\text { Noraxon Inc., USA) } \\
\text { and electrode patches } \\
\text { (Medi-Trace 200, } \\
\text { Kendall, USA) }\end{array}$ & $\begin{array}{l}\text { PFPS patients' } \\
\text { muscle functions } \\
\text { improved by } \\
\text { enhancing muscle } \\
\text { control and } \\
\text { response ability } \\
\text { using EMG } \\
\text { biofeedback with } \\
\text { which real-time } \\
\text { bioinformation on } \\
\text { the muscles is } \\
\text { provided during } \\
\text { closed kinetic chain } \\
\text { exercise in order to } \\
\text { raise treatment } \\
\text { efficiency. }\end{array}$ \\
\hline $\begin{array}{l}\text { 9) } \\
\text { Hwangbo, } \\
(2015)\end{array}$ & $\begin{array}{l}\text { The purpose of this } \\
\text { study was to identify } \\
\text { the effects of } \\
\text { performing squat } \\
\text { exercises with } \\
\text { visual feedback on the } \\
\text { activation of the vastus } \\
\text { medialis oblique } \\
\text { (VMO) and vastus } \\
\text { lateralis (VL) muscles } \\
\text { in young } \\
\text { adults with an } \\
\text { increased quadriceps } \\
\text { angle (Q-angle). }\end{array}$ & $\begin{array}{l}20 \text { young adults with } \\
\text { an increased Q-angle, } \\
\text { who were then divided } \\
\text { into a squat group } \\
\text { that received visual } \\
\text { feedback (VSG, } n=10 \text { ) } \\
\text { and a squat group that } \\
\text { received no visual } \\
\text { feedback }(\mathrm{SG}, \mathrm{n}=10 \text { ). }\end{array}$ & $\begin{array}{l}\text { squat exercises with a } \\
\text { maximum of } 90^{\circ} \text { of knee } \\
\text { flexion within a route } \\
\text { marked on a mirror }\end{array}$ & $\begin{array}{l}\text { The activation of VL } \\
\text { and VMO was recorded } \\
\text { with surface } \\
\text { electromyography } \\
\text { (EMG) } \\
\text { during }\end{array}$ & $\begin{array}{l}\text { This study } \\
\text { confrmed that } \\
\text { squat exercises with } \\
\text { visual feedback are } \\
\text { effective in } \\
\text { activation of the } \\
\text { VMO and VL } \\
\text { muscles. The } \\
\text { fndings are } \\
\text { meaningful in terms } \\
\text { of preventing the } \\
\text { occurrence of } \\
\text { patellofemoral pain. }\end{array}$ \\
\hline
\end{tabular}

Table 2: Studies excluded from the review

\begin{tabular}{|c|c|c|}
\hline No. & The study & Reason for exclusion \\
\hline 1 & Harrison et al. (1999) & No specification of muscles \\
\hline 2 & Witvroue et al. (2003) & Focus on VMO and VL reflex response \\
\hline 3 & IRISH et al. (2010) & Inclusion of healthy individuals \\
\hline 4 & Hashmiy et al (2011) & Case-control study Use of MRI for assessment of VMO size in individuals with PFPS \\
\hline 5 & Pattyn et al. (2011) & No specification of muscles \\
\hline 6 & Ismail et al. (2013) & Not RCT \\
\hline 7 & Chang et al. (2014) & cross-sectional study \\
\hline 8 & Lam, 2001 2015 & lack of a control group \\
\hline 9 & Miao, 2015 \\
\hline 10 & O'Sullivan \& Popelas 2005 & Case-control study \\
\hline 11 & Tang, 2001 & \\
\hline
\end{tabular}


4. Results

\subsection{Study selection}

A number of 91 possible studies were obtained from the search of the electronic databases and the manual search of the references listed in every relevant article. Of these, 39 studies were eliminated after the titles and abstracts were screened because they failed to satisfy the inclusion and exclusion criteria. Regarding the rest of 52 studies, their full texts were downloaded and scrutinised, and after the elimination of duplicates from different databases, a number of nine full-text studies were obtained. These were again subjected to appraisal with respect to the inclusion and exclusion criteria, as shown in Figure 1.

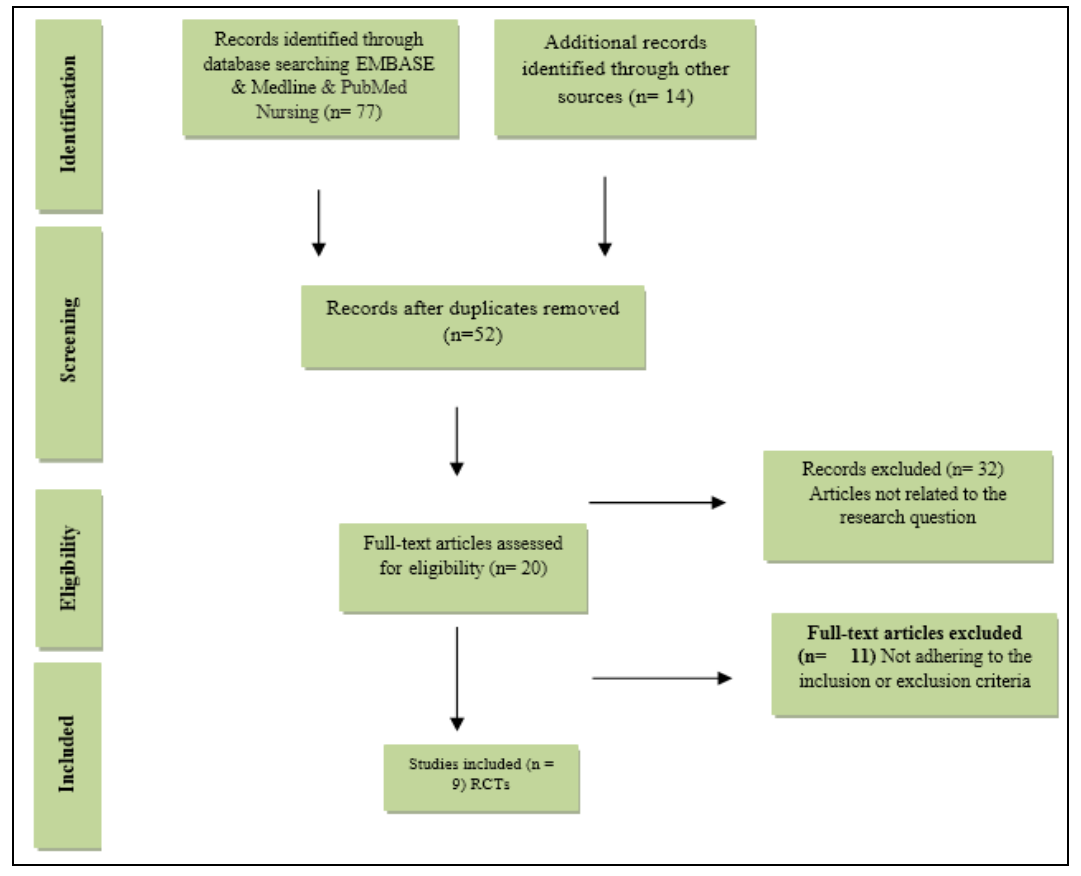

Fig 1: The outcome of the application of the search strategy PRISMA flow diagram

The nine RCTs obtained from the electronic and manual search for inclusion in the review were Fehr et al. (2006) ${ }^{[14]}$, Coqueiro et al. (2005) ${ }^{[10]}$ and Santos et al. (2008) ${ }^{[38]}$, all from Brazil, Laprade et al. (1998) ${ }^{[28]}$ (Canada), Syme et al. (2009) ${ }^{[44]}$ (UK), Boling et al. (2006) ${ }^{[4]}$ (US), Song et al. (2009) ${ }^{[41]}$ (Taiwan), and Kang, Kim and Kim, (2014) ${ }^{[26]}$ and Hwangbo (2015) ${ }^{[23]}$, both from the Republic of Korea.

\subsection{Assessment of the quality of methodology}

In accordance with Hill and Spittlehouse (2001) ${ }^{[22]}$, the methodological quality was evaluated in order to make sure that there was good understanding of the research evidence and that there was satisfactory agreement between theoretical and practical aspects.

The critical assessment instrument PEDro, consisting of eleven items, is useful for the measurement of internal validity and recording of statistical measures, and therefore it was applied to assess the quality of the research methodology of each selected study (PEDro, 1999).

Table 2: PEDro criteria

\begin{tabular}{|c|c|c|c|c|c|c|c|c|c|}
\hline PEDro criteria & $\begin{array}{l}\text { 1) Fehr } \\
\text { et al., } \\
2006\end{array}$ & $\begin{array}{l}\text { 2) Laprade } \\
\text { et al., } 1998\end{array}$ & $\begin{array}{l}\text { 3) Coqueiro } \\
\text { et al., } 2005\end{array}$ & $\begin{array}{l}\text { 4) Santos } \\
\text { et al., } 2008\end{array}$ & $\begin{array}{l}\text { 5) syme } \\
\text { et al., } \\
2009\end{array}$ & $\begin{array}{l}\text { 6) Boling } \\
\text { et al., } 2006\end{array}$ & $\begin{array}{l}\text { 7) Song } \\
\text { et al., } \\
2009\end{array}$ & $\begin{array}{l}\text { 8) Kang } \\
\text { et al., } \\
2014 \\
\end{array}$ & $\begin{array}{c}9) \\
\text { Hwangbo, } \\
2015 \\
\end{array}$ \\
\hline 1.Eligibility criteria & Yes & Yes & Yes & Yes & Yes & Yes & Yes & Yes & Yes \\
\hline 2.Random allocation & No & No & No & $\mathrm{N} / \mathrm{M}$ & Yes & No & Yes & Yes & No \\
\hline $\begin{array}{l}\text { 3.Concealed } \\
\text { allocation }\end{array}$ & No & No & No & NO & Yes & No & Yes & $\mathrm{N} / \mathrm{M}$ & No \\
\hline $\begin{array}{l}\text { 4.Comparable } \\
\text { baseline }\end{array}$ & No & No & Yes & Yes & Yes & Yes & Yes & Yes & Yes \\
\hline 5.Subjects blinded & No & No & No & No & No & No & No & No & No \\
\hline 6.Therapists blinded & No & No & No & No & No & No & Yes & No & No \\
\hline 7.Assessors blinded & No & No & No & No & Yes & No & Yes & No & No \\
\hline $\begin{array}{l}\text { 8. Outcomes for } 85 \% \\
\text { of initial participants }\end{array}$ & $\mathrm{N} / \mathrm{M}$ & $\mathrm{N} / \mathrm{M}$ & $\mathrm{N} / \mathrm{M}$ & Yes & Yes & Yes & Yes & Yes & Yes \\
\hline $\begin{array}{l}\text { 9.Intention-to- treat } \\
\text { analysis }\end{array}$ & Yes & Yes & Yes & Yes & Yes & Yes & Yes & Yes & Yes \\
\hline $\begin{array}{l}\text { 10. Between group } \\
\text { stat comparison }\end{array}$ & No & No & Yes & Yes & Yes & Yes & Yes & Yes & Yes \\
\hline $\begin{array}{c}\text { 11.Point \& variability } \\
\text { measures }\end{array}$ & Yes & Yes & Yes & Yes & Yes & Yes & Yes & Yes & Yes \\
\hline Total score & 3 & 3 & 5 & 6 & 9 & 6 & 10 & 7 & 6 \\
\hline
\end{tabular}




\subsection{Quality of evidence}

The studies conducted by Syme et al. (2009) and Song et al. (2009) ${ }^{[41]}$, Kang et al. (2014) were demonstrated good quality $(\geq 7)$, according to the cut-off points established earlier. Meanwhile, the studies undertaken by Coqueiro et al. (2005) ${ }^{[10]}$, Santos et al. (2008) ${ }^{[38]}$, Boling et al. (2006) ${ }^{[4]}$ and Hwangbo (2015) ${ }^{[23]}$ deemed to be of moderate quality $(<7)$, whereas the studies by Fehr et al. (2006) ${ }^{[14]}$ and Laprade et al. $(1998)^{[28]}$ were of poor quality $(<4)$.

\subsection{Summary and evaluation of the evidence}

Laprade et al. (1998) ${ }^{[28]}$ compared individuals with and without PFPS in terms of VMO activation based on five isometric exercises. The participants were all female and 24 years old, and of the total of 27 participants, 19 did not have PFPS whereas 8 had the condition. The participants were asked to perform two submaximal isometric contractions and four maximal isometric knee extension contractions, whilst they were attached bipolar gold-plated electrodes to document the raw EMG signals. According to the results, there was no notable difference between the participants with and without PFPS with regard to EMG VMO or VL proportions. Nonetheless, the study was graded only a 3 on the PEDro scale of methodological quality because it did not apply randomisation.

Coqueiro et al. (2005) ${ }^{[10]}$ investigated the effect of semi-squat exercises with hip adduction on the VMO and VL muscle activity. The research sample consisted of 20 participants, of which ten had PFPS $(21.8 \pm 2.52$ years old $)$ and ten did not have PFPS $(23.2 \pm 2.65$ years old). They were asked to carry out double-leg semi-squats (DLSS) with and without hip adduction. The electrical signals from the VMO and VL muscles were documented with active differential surface EMG electrodes (Lynx Electronics Technologies, Brazil). No preferential activation was exhibited by the VMO muscle. A score of 5 on the PEDro scale was awarded to this study, indicating moderate methodological quality.

Syme et al. (2009) conducted an RCT on 69 participants with PFPS to investigate rehabilitation outcomes of interventions that involved retraining the quadriceps femoris element of the VMO and strengthening of the entire quadriceps femoris. To ensure that only the VMO muscle was activated and retrained and not the VL muscle, physiotherapy exercises were administered with a dual channel surface electromyographic biofeedback unit. Two flexible electrogoniometers permitted the measurement of knee extension and flexion angles. However, as stressed by Rowe et al. (2001) ${ }^{[37]}$, this approach was found to be valid and reliable only for people who did not suffer from PFPS. The findings did not confirm that selective VMO activation led to better outcomes compared to open and closed chain strengthening exercises.

The pragmatic nature of the applied interventions hindered an evaluation of the extent to which the different elements of the rehabilitation program were significant. In spite of this, studies employing just one intervention contradict clinical practice, as physiotherapists typically employ more than one intervention strategy (Bithell, 2000; Grimmer et al., 2004) ${ }^{[1,18]}$. Hence, it can be said that the nature of the employed interventions can contribute to make the results of a study more valid and more amenable to generalisation. Meanwhile, a series of relevant issues were highlighted in the study as well.

Clinicians should not attribute greater importance to selective activation before the rehabilitation program is commenced, especially in the case of individuals with chronic conditions whose participation is significantly restricted. This conclusion is derived from the fact that the study did not confirm that selective VMO activation was more effective compared to open and closed kinetic chain strengthening exercises in enhancing rehabilitation outcomes (Witvrouw et al., 2004; Bolgla and Boling, 2011) ${ }^{[48,2]}$. Nevertheless, the study scored 9 on the PEDro scale with regard to methodological quality.

A total of 28 participants in the age range 18-42 years old, of which 14 were assigned to the control group and 14 to the experimental group, were recruited by Boling et al. (2006) ${ }^{[4]}$ to examine how weight-bearing rehabilitation affected VMO and VL electromyographic activity, pain and function. The rehabilitation strategy applied to the experimental group comprising five males and nine females with an average age of 24 years old consisted of weight-bearing exercises intended to alter muscle pain, function and activation patterns by balancing, stretching and strengthening the quadriceps and hip abductor muscles. Participants with PFPS responded favourably and immediately to this intervention.

The low reliability of the electromyographic measures and the absence of a control group with PFPS diminished the validity of the results obtained. The lack of a research design framework also constituted a limitation.

Song et al. (2009) ${ }^{[41]}$ recruited 89 participants with PFPS for their RCT and randomly assigned them to one of three groups, namely, hip adduction combined with leg-press exercise (LPHA group), leg-press exercise only (LP group), and no exercise (control group). The duration of the rehabilitation program was two months with three sessions weekly. The maximum levels of pain were measured before and following training on the basis of a $100-\mathrm{mm}$ visual analog scale (VAS) and Lysholm scale scores. The characteristics of low pain, improved function and VMO hypertrophy were exhibited by the groups subjected to exercise activities. The study adopted a blind or non-discriminatory approach, with a single physical therapist unaware of the research goals carrying out the randomisation and interventions. Furthermore, two sessions of evaluation were undertaken by another physical therapist who had no knowledge of the manner in which the participants were divided into groups.

According to the results obtained, a rehabilitation program implemented over a period of two months and comprising simple LP training ( $45^{\circ}$ flexion to full knee flexion) and stretching significantly improved VMO hypertrophy and knee function whilst also reducing pain. Nonetheless, the study scored only 10 on the PEDro scale in terms of methodological quality.

There are several limitations to this study. The fact that the healthy participants did not have any pain or symptoms associated with the patella and neither did their muscle activity show similarity with that of participants with PFPS is a significant limitation. Moreover, the sample size was not large enough to permit the results to be generalised. Hence, the study scored 6 on the PEDro scale with regard to methodological quality.

\section{Discussion}

\subsection{Analysis of reviewed studies}

Closed kinetic chain and weight-bearing exercises (e.g. double-leg squat, leg-press and lung exercises) were administered by Irish et al. (2010) ${ }^{[24]}$ as well as Coqueiro et al. (2005) ${ }^{[10]}$ with the purpose of strengthening the VMO muscle. The results they obtained provided evidence that these types of exercises are effective in activating the VMO and VL muscles. Furthermore, performance of squat exercises (i.e. mini-squat, semi-squat, wall-sit and wall-slide exercises) 
together with hip adduction enhanced quadriceps activation not only in participants without PFPS, but also in those with PFPS.

An additional observation reported by Coqueiro et al. (2005) ${ }^{[10]}$ was that closed kinetic chain exercises augmented VMO activation more than VL activation. By contrast, performance of closed kinetic chain exercises alongside weight-bearing exercises led to an increase in pulling strength and intraarticular pressure, worsening PFPS symptoms.

On the other hand, Spairani et al. (2012) ${ }^{[42]}$ did not observe activation in the VMO that was significant enough to augment patellar tracking, therefore concluding that open kinetic chain exercises did not have a marked impact on PFPS rehabilitation. By contrast, Chang et al. (2015) ${ }^{[7]}$ stated that application of sling open chain knee extension (SOCKE) exercise in conjunction with sling exercise therapy (SET) intensified VMO activity compared to VL activity.

Most of the studies that were reviewed compared the responses of the VMO and VL muscles of participants with PFPS to open and closed kinetic chain exercises, but none of them compared experimental and placebo control groups. This may be explained in terms of the ethical issues associated with denial of therapy or the problems posed by the development of an effective physiotherapy placebo. In spite of this, however, the study findings lend credence to the efficiency of open and closed kinetic chain exercises in alleviating pain caused by PFPS.

The limited sample sizes meant that effects could be distinguished between the research groups only if they were sufficiently pronounced. Furthermore, intervention effects could not be monitored in the long-term in many experimental group participants who responded positively to the intervention, because a proportion of $48 \%$ of them withdrew from the research after twelve months. Hence, the credibility of the results is questionable. Even so, both open and closed kinetic chain exercises were found by many of the reviewed studies to be beneficial for improving pain and function in the long-term.

Even though physiotherapy was found to determine a reduction in pain, no definitive evidence was produced regarding the greater efficiency of one intervention type over another. Nevertheless, there can be no doubt that, of the various strengthening methods, muscle function benefitted the most from open and closed kinetic chain exercises.

The lack of agreement between the findings of the different reviewed studies may be due to discrepancies in methodology. Another potential cause is the fact that the open and closed kinetic exercises were not tailored to each participants according to individual problems (e.g. dysfunctional muscle motor control or excessive tightness of soft tissues surrounding the patellofemoral joint), but instead were applied in a standardised manner, with potential adverse implications for intervention outcome. This second cause ought to be inspected further with clinical trials.

Trials that are more scientifically sound should be undertaken to determine how efficient the applied interventions were. According to current evidence, an intervention approach integrating education, stretching and quadriceps strengthening, and application of soft corrective foot orthoses should be adopted to treat PFPS successfully.

\subsection{Shortcomings}

Two limitations of methodology are demonstrated by the present systematic review. The first limitation is that, owing to a desire to ensure quality, the review did not include data sources that were not published (i.e. "grey literature"), but only studies that were peer-reviewed. Hence, this might have given rise to a publication bias that could have affected the results obtained. The other limitation is that, to save costs, the review did not include studies written in languages other than English.

\subsection{Significance for practice}

It is clear that pain associated with PFPS benefits from open and closed kinetic chain exercises, at least in the short-term; however, it is still unclear whether the efficiency of these exercises surpasses that of exercises that can be undertaken at home. Therefore, it is important to determine the factors related to PFPS development to devise efficient interventions that can be adapted to the requirements of each PFPS patient. Future research should then focus on the formulation of casespecific rehabilitation interventions and reliable measures of outcome evaluation.

\section{Conclusion}

The trials under review were too few in number and were inconsistent with regard to rehabilitation strategies and outcome assessment. They underline the necessity for reviewing RCT trials on a wider scale as the evidence they supplied in support of use of open and closed kinetic chain exercises was insufficient. Trials have to be comparable in terms of participant traits, intervention and outcome assessment to improve the validity of the conclusions drawn. Additionally, it was not possible to definitely say whether one intervention was better than another, because different interventions were implemented in the reviewed trials. Furthermore, future research should also include placebocontrolled trials to ascertain the efficiency of various interventions.

\section{References}

1. Bithell C. Evidence-based Physiotherapy: Some thoughts on 'best evidence'. Physiotherapy. 2000; 86(2):58-59.

2. Bolgla LA, Boling MC. An update for the conservative management of patellofemoral pain syndrome: A systematic review of the literature from 2000 to 2010 . International journal of sports physical therapy. 2011; 6(2): 112.

3. Bolgla L, Malone T. Exercise prescription and patellofemoral pain: evidence for rehabilitation. J Sports Rehabil, 2005; 14:72-88.

4. Boling MC, Bolgla LA, Mattacola CG, Uhl TL, Hosey RG. Outcomes of a weight-bearing rehabilitation program for patients diagnosed with patellofemoral pain syndrome. Archives of physical medicine and rehabilitation. 2006; 87(11):1428-1435.

5. Britton A, Cousins A. Study skills: a guide for lifelong learners. London: Distance Learning Centre. 1998.

6. Chang WD, Huang WS, Lee CL, Lin HY, Lai PT. Effects of open and closed kinetic chains of sling exercise therapy on the muscle activity of the vastus medialis oblique and vastus lateralis. Journal of physical therapy science. 2014; 26(9):1363.

7. Chang WD, Huang WS, Lai PT. Muscle Activation of Vastus Medialis Oblique and Vastus Lateralis in SlingBased Exercises in Patients with Patellofemoral Pain Syndrome: A Cross-Over Study. Evidence-Based Complementary and Alternative Medicine. 2015.

8. Collins JA, Fauser BC. Balancing the strengths of systematic and narrative reviews. Human Reproduction 
Update. 2005; 11(2):103-104.

9. Concato J, Shah N, Horwitz RI. Randomized, controlled trials, observational studies, and the hierarchy of research designs. New England Journal of Medicine. 2000; 342(25):1887-1892.

10. Coqueiro KRR, Bevilaqua-Grossi D, Bérzin F, Soares AB, Candolo C, Monteiro-Pedro V. Analysis on the activation of the VMO and VLL muscles during semisquat exercises with and without hip adduction in individuals with patellofemoral pain syndrome. Journal of Electromyography and Kinesiology. 2005; 15(6):596-603.

11. Cronin P, Ryan F, Coughlan M. Undertaking a literature review: A step-by-step approach. British Journal of Nursing. 2008; 17(1):38-43.

12. Dannelly BD, Otey SC, Croy T, Harrison B, Rynders C A, Hertel $\mathrm{JN}$ et al. The effectiveness of traditional and sling exercise strength training in women. The Journal of Strength \& Conditioning Research. 2011; 25(2):464-471.

13. Fagan V, Delahunt E. Patellofemoral pain syndrome: a review on the associated neuromuscular deficits and current treatment options. British journal of sports medicine. 2008; 42(10):789-795.

14. Fehr GL, Cliquet Junior A, Cacho ÊWA, Miranda JBD. Effectiveness of the open and closed kinetic chain exercises in the treatment of the patellofemoral pain syndrome. Revista Brasileira de Medicina do Esporte. 2006; 12(2):66-70.

15. Fredericson M, Yoon K. Physical examination and patellofemoral pain syndrome. American journal of physical medicine \& rehabilitation. 2006; 85(3):234-243.

16. Giles LS, Webster KE, McClelland JA, Cook J. Does quadriceps atrophy exist in individuals with patellofemoral pain? A systematic literature review with meta-analysis. Journal of Orthopaedic \& Sports Physical Therapy. 2013; 43(11):766-776.

17. Greenhalgh T. How to read a paper: the basics of evidence based medicine. 2nd ed. London: BMJ, 2001.

18. Grimmer K, Bialocerkowski A, Kumar S, Milanese S. Implementing evidence in clinical practice: the 'therapies' dilemma. Physiotherapy, 2004; 90(4):189-194.

19. Harrison L, Sheppard MS, McQuarrie AM. Feature Articles-A Randomized Controlled Trial of Physical Therapy Treatment Programs in Patellofemoral Pain Syndrome. Physiotherapy Canada. 1999; 51(2):93-100.

20. Hashim M, Hasnimy A, Choo LAA. Development of Neuromuscular Control Exercise Protocol of the Knee with Patellofemoral Pain Syndrome (PFPS): A Concept Paper. Journal of edupres. 2011; 1:55-64.

21. Higgins J, Green S. Intention to Treat Issue, Cochrane Handbook for Systematic Reviews of Interventions 4.2.6 [updated September 2006]; Section 8.4. The Cochrane Library, 2006. Chichester, UK: John Wiley \& Sons, Ltd., 2006, 4.

22. Hill A, Spittlehouse C. What is critical appraisal? Oxford: Bandolier, 2001.

23. Hwangbo PN. The effects of squatting with visual feedback on the muscle activation of the vastus medialis oblique and the vastus lateralis in young adults with an increased quadriceps angle. Journal of Physical Therapy Science. 2015; 27(5):1507-1510.

24. Irish SE, Millward AJ, Wride J, Haas BM, Shum GL. The effect of closed-kinetic chain exercises and open-kinetic chain exercise on the muscle activity of vastus medialis oblique and vastus lateralis. The Journal of Strength \& Conditioning Research. 2010; 24(5):1256-1262.
25. Ismail MM, Gamaleldein MH, Hassa KA. Closed kinetic chain exercises with or without additional hip strengthening exercises in management of patellofemoral pain syndrome: a randomized controlled trial. European journal of physical and rehabilitation medicine. 2013; 49(5):687-698.

26. Kang JY, Kim TG, Kim KY. The effects of closed kinetic chain exercise using EMG biofeedback on PFPS patients pain and muscle functions. Int J Biosci Biotechnol. 2014; 6:55-62.

27. Lam PL, Ng GY. Activation of the quadriceps muscle during semi squatting with different hip and knee positions in patients with anterior knee pain. American journal of physical medicine \& rehabilitation. 2001; 80(11):804-808.

28. Laprade J, Culham E, Brouwer B. Comparison of five isometric exercises in the recruitment of the vastus medialis oblique in persons with and without patellofemoral pain syndrome. Journal of Orthopaedic \& Sports Physical Therapy. 1998; 27(3):197-204.

29. Lankhorst NE, Bierma-Zeinstra SM, van Middelkoop M. Risk factors for patellofemoral pain syndrome: a systematic review. Journal of orthopaedic \& sports physical therapy. 2012; 42(2):81-A12.

30. Megens A, Harris S. Physical therapist management of lymphedema following treatment for breast cancer: a critical review of its effectiveness. Phys Ther. 1998; 78:1302.

31. Miao P, Xu Y, Pan C, Liu H, Wang C. Vastus medialis oblique and vastus lateralis activity during a double-leg semisquat with or without hip adduction in patients with patellofemoral pain syndrome. BMC musculoskeletal disorders. 2015; 16(1):1.

32. Nunes GS, Stapait EL, Kirsten MH, de Noronha M, Santos GM. Clinical test for diagnosis of patellofemoral pain syndrome: Systematic review with meta-analysis. Physical Therapy in Sport. 2013; 14(1):54-59.

33. O'sullivan SP, Popelas CA. Activation of vastus medialis obliquus among individuals with patellofemoral pain syndrome. The Journal of Strength \& Conditioning Research. 2005; 19(2):302-304.

34. Pattyn E, Verdonk P, Steyaert A, Bossche LV, Van den Broecke W, Thijs $\mathrm{Y}$ et al. Vastus medialis obliquus atrophy does it exist in Patellofemoral Pain Syndrome?. The American journal of sports medicine. 2011; 39(7):1450-1455.

35. Powers CM. Patellar kinematics, part I: the influence of vastus muscle activity in subjects with and without patellofemoral pain. Physical therapy. 2000; 80(10):956964.

36. Rochon PA, Gurwitz JH, Sykora K, Mamdani M, Streiner DL, Garfinkel S et al. Reader's guide to critical appraisal of cohort studies: 1. role and design. British Medical Journal. 2005; 330:895-897.

37. Roush JR, Bay RC, Prevalence of anterior knee pain in 18-35 year-old females. International journal of sports physical therapy. 2012; 7(4): 396.

38. Rowe PJ, Myles CM, Hillmann SJ, Hazlewood ME. Validation of flexible electrogoniometry as a measure of joint kinematics. Physiotherapy. 2001; 87(9):479-488.

39. Santos EP, Bessa SNF, Lins CAA, Marinho AMF, Silva KMP, Brasileiro JS. Electromyographic activity of vastus medialis obliquus and vastus lateralis muscles during functional activities in subjects with patellofemoral pain syndrome. Brazilian Journal of Physical Therapy. 2008; 
12(4):304-310.

40. Smith TO, Nichols R, Gilding E, Donell ST. Are location, proportion and length of VM patellar attachment aetiological factors in patellofemoral dysfunction? A systematic review. European Journal of Orthopaedic Surgery \& Traumatology. 2009a; 19(2):63-73.

41. Smith TO, Bowyer D, Dixon J, Stephenson R, Chester R, Donell ST. Can vastus medialis oblique be preferentially activated? A systematic review of electromyographic studies. Physiotherapy theory and practice. 2009b; 25(2):69-98.

42. Song CY, Lin YF, Wei TC, Lin DH, Yen TY, Jan MH. Surplus value of hip adduction in leg-press exercise in patients with patellofemoral pain syndrome: a randomized controlled trial. Physical therapy, 2009; 89(5):409-418.

43. Spairani L, Barbero M, Cescon C, Combi F, Gemelli T, Giovanetti $G$ et al. An electromyographic study of the vastii muscles during open and closed kinetic chain submaximal isometric exercises. International journal of sports physical therapy. 2012; 7(6):617.

44. Stensdotter AK, Hodges P, Mellor R, Sundelin G, HägerRoss C. Quadriceps activation in closed and in open kinetic chain exercise. Medicine \& Science in Sports \& Exercise. 2003; 35(12):2043-2047.

45. Syme G, Rowe P, Martin D, Daly G. Disability in patients with chronic patellofemoral pain syndrome: a randomised controlled trial of VMO selective training versus general quadriceps strengthening. Manual therapy. 2009; 14(3):252-263.

46. Tang SF, Chen CK, Hsu R, Chou SW, Hong WH, Lew HL. Vastus medialis obliquus and vastus lateralis activity in open and closed kinetic chain exercises in patients with patellofemoral pain syndrome: an electromyographic study. Archives of physical medicine and rehabilitation. 2001; 82(10):1441-1445.

47. Van de Voorde C, Leonard C. Search for Evidence and Critical Appraisal: Health Services Research (HSR). Belgian Health Care Knowledge Centre, 2007.

48. Witvrouw E, Cambier D, Danneels L, Bellemans J, Werner S, Almqvist $\mathrm{F}$ et al. The effect of exercise regimens on reflex response time of the vasti muscles in patients with anterior knee pain: a prospective randomized intervention study. Scandinavian journal of medicine \& science in sports. 2003; 13(4):251-258.

49. Witvrouw E, Danneels L, Van Tiggelen D, Willems TM, Cambier D. Open versus closed kinetic chain exercises in patellofemoral pain a 5-year prospective randomized study. The American Journal of sports medicine. 2004; 32(5):1122-1130.

50. White A, Schmidt K. Systematic literature reviews. Complement Ther Med. 2005; 13:54-60. https://www.pedro.org.au/english/downloads/pedro-scale/ 